\title{
Motivational parameters in ethanol-induced state-dependent dissociation of avoidance learning*
}

\author{
FRANK A. HOLLOWAY† and RICHARD A. WANSLEY \\ University of Oklahoma Health Sciences Center, Oklahoma City, Oklahoma 73190
}

\begin{abstract}
The effects of ethanol on the acquisition and retention performance of a one-way active avoidance response were examined in rats as a function of the intertrial time on the grid floor (TGF). During acquisition on Day 1, ethanol did not affect performance. However, animals having shorter TGF periods required significantly fewer trials to reach criterion performance than did animals having longer TGF periods. During the retraining session on Day 2, an overall state-dependent effect was observed, i.e., animals receiving the same drug on Days 1 and 2 required significantly fewer trials to reacquire criterion performance than animals receiving different drugs on Days 1 and 2. Furthermore, the nature of these state-dependent effects varied as a function of the duration of TGF. Animals receiving ethanol on Day 1 and saline on Day 2 required more trials to reach the criterion than their controls regardless of the TGF, while animals receiving saline on Day 1 and ethanol on Day 2 only required more trials than their controls at the longer TGF periods. These results imply that dissociation of learning in the ethanol-saline group and the saline-ethanol group may be differentially influenced by certain motivational factors.
\end{abstract}

Ethanol-induced dissociation of avoidance learning has been demonstrated in a variety of tasks (Crow, 1966; Holloway, 1972). The drug transfer paradigm employed in these studies involved training on Day 1 under either saline or ethanol drug states and testing (i.e., retraining) on Day 2 with the same or opposite drug states. In the Holloway study, a one-way active avoidance procedure yielded "symmetrical" state-dependent learning results in which the two groups with different drugs on Days 1 and 2 (i.e., the ethanol-saline or ES group and the saline-ethanol or SE group) had poorer retraining performance than their appropriate controls having the same drugs on Days 1 and 2 (i.e., the ethanol-ethanol or EE group and the saline-saline or SS group). With the other avoidance tasks-two-way active avoidance, step-down passive avoidance, and step-through passive a voidance-" "asymmetrical" state-dependent learning results were obtained, i.e., the ES groups had poorer Day 2 performance than the $\mathrm{EE}$ group, but no differences in Day 2 performance were found between the SS and SE groups. The author suggested that different mechanisms may mediate impaired Day 2 performance in the SE and ES groups and that differences in training conditions, the extent of training, or the nature of the response learned may be variables affecting the production of symmetrical or asymmetrical state-dependent learning results.

Since the one-way active avoidance task uniquely produced symmetrical dissociation effects in the Holloway (1972) study, this task provides a good model to examine the role of training-testing procedures in the state-dependent phenomena and permits convenient

*This research was supported in part by Public Health Service Grant 14072 awarded to the senior author's project at the Oklahoma Center for Alcohol Related Studies.

+Address reprints to: Frank A. Holloway, Department of Psychiatry and Behavioral Sciences, University of Oklahoma Health Sciences Center, 800 N.E. 13th, P.O. Box 26901, Oklahoma City, Oklahoma 73190. manipulation of the temporal parameters of training. Recently, Holloway and Wansley ${ }^{1}$ have shown that acquisition of avoidance responding in this one-way active avoidance task was superior under conditions of a brief intertrial exposure to the grid floor of the apparatus (where shock was delivered) than under conditions of longer periods of exposure to the grid floor between trials. These results were interpreted as indicating that motivation for the learned avoidance response was less with longer periods of exposure to the grid floor due to a decrease in, or extinction of, fear associated with that part of the apparatus. This earlier study constituted the initial part of the present investigation, which was designed to focus on the role of those training-testing conditions producing differences in avoidance acquisition on ethanol-induced dissociation of such learning. More specifically, the present study examined acquisition and responding in the one-way task, employing (1) a drug transfer paradigm involving saline and ethanol, and (2) groups trained and tested under conditions in which the period of time spent on the grid floor (TGF) between trials was varied.

\section{METHOD}

\section{Subjects}

The Ss in this experiment were 160 male albino rats (Sasco), ranging in weight from 250 to $367 \mathrm{~g}$ at the beginning of the experiment. All Ss were housed individually and were maintained on an ad lib food and water schedule. Animals were placed on a rigid 12-h light $(0800-2000)$ and 12 -h dark (2000-0800) cycle for at least 2 weeks prior to the experiment. The Ss were randomly assigned to one of 16 independent groups $(\mathrm{N}=10$ per group) involving four TGF periods $(3,6,30,60 \mathrm{sec})$ and four drug treatment conditions on Days 1 and 2 (SS, SE, $\mathrm{EE}$, and ES).

\footnotetext{
Apparatus

The apparatus was an automated "step-up" active avoidance task, described in detail elsewhere (Holloway, 1972). Briefly, the
} 
Table 1

Day 1 Training Performance (Means)

\begin{tabular}{|c|c|c|c|c|c|}
\hline \multirow[b]{2}{*}{ Measure } & \multicolumn{4}{|c|}{ Intertrial Interval } & \multirow[b]{2}{*}{ Overall } \\
\hline & $3 \mathrm{Sec}$ & $6 \mathrm{Sec}$ & $30 \mathrm{Sec}$ & $60 \mathrm{Sec}$ & \\
\hline \multicolumn{6}{|c|}{ Trials to Criterion } \\
\hline Saline & 12.0 & 14.2 & 15.7 & 23.4 & 16.3 \\
\hline Ethanol & 9.8 & 13.5 & 14.4 & 20.8 & 14.6 \\
\hline \multicolumn{6}{|l|}{ Percent CAR } \\
\hline Saline & 56.1 & 50.4 & 43.2 & 35.4 & 46.3 \\
\hline Ethanol & 50.5 & 43.0 & 45.0 & 36.9 & 43.8 \\
\hline
\end{tabular}

apparatus consisted of a rectangular Plexiglas chamber $(50.8 \mathrm{~cm}$ high $\times 38.1 \mathrm{~cm}$ wide $\times 38.1 \mathrm{~cm}$ deep). A retractable platform $(12.7 \mathrm{~cm}$ square) could be electromechanically introduced into or withdrawn from the chamber through a slot in one of the walls, $15.2 \mathrm{~cm}$ above the grid floor. The stainless steel bars of the grid floor were attached to a constant wattage shock generator-scrambler (BRS No. SGS-001). The entire apparatus was housed in a dim sound-attenuated room.

\section{Conditioning Procedures}

On Day 1, without any prior adaptation to the apparatus, each animal was placed on the grid floor of the chamber. One minute later, the first trial was begun manually. The platform was introduced into the chamber for the first time, followed $10 \mathrm{sec}$ later by the delivery of $0.1 \mathrm{~W}$ of shock to the grid floor bars (maximum shock duration $=15 \mathrm{sec}$ ). An avoidance or escape response occurred when the animal climbed onto the platform, an event detected by the gating of the platform microswitch closure and the interruption of one of two photocells located above the platform. Once a response was made, the platform remained out for an additional $15 \mathrm{sec}$ and then was withdrawn into the chamber wall, allowing the animal to drop to the floor (where shock was then no longer present). The period of time between the retraction of the platform from the chamber to its introduction on the next trial (the TGF period) depended on the group but was the same for a given group on both days of training. On both Days 1 and $2(24 \mathrm{~h}$ apart), avoidance training continued until the animal met a criterion of four conditioned avoidance responses (CAR) on four consecutive trials. A CAR occurred when the animal climbed onto the platform after its introduction into the chamber but before the onset of grid shock. Two behavioral measures were obtained for each day's performance: (1) trials to criterion, and (2) percentage of CARs (\%CARs).

\section{Drug Injection Procedures}

Fifteen minutes prior to each training session, all Ss were injected intraperitoneally (IP) with either a $0.9 \%$ saline solution or a $10 \%$ ethanol solution (prepared with $95 \%$ ethanol and $0.9 \%$ saline on a weight/volume basis). The dosage employed was $1.5 \mathrm{~g} / \mathrm{kg}$ body weight. A volume of saline equivalent to that for the ethanol dose was injected on saline sessions.

\section{RESULTS}

\section{Day 1 Training}

The mean acquisition performance for the various groups is presented in Table 1. There were no significant ( $p>.05)$ differences between saline and ethanol groups at any of the TGF conditions on Day 1 . However, there were significant main effects for the TGF variable $(\mathrm{df}=$ $3 / 152)$ on both the trials to criterion $(F=32.40$, $\mathrm{p}<.01)$ and percentage of CARs $(\mathrm{F}=16.15, \mathrm{p}<.01)$ measures. These data are similar to those reported for control groups in the previous report (Holloway \&
Wansley $^{\mathbf{1}}$ ) in that the number of trials required to achieve criterion performance increased with increases in the duration of the TGF period.

\section{Day 2 Retraining}

The mean performance for the various behavioral indices of avoidance conditioning on Day 2 is presented in Fig. 1. Since there were no significant differences between ethanol and saline groups on Day 1 and since all Ss were trained to a common level of performance on Day 1, three-way analyses of variance were performed on the Day 2 performance measures (TGF, drug on Day 1, and drug on Day 2).

The most consistent finding across the several groups and behavioral measures was significant interaction
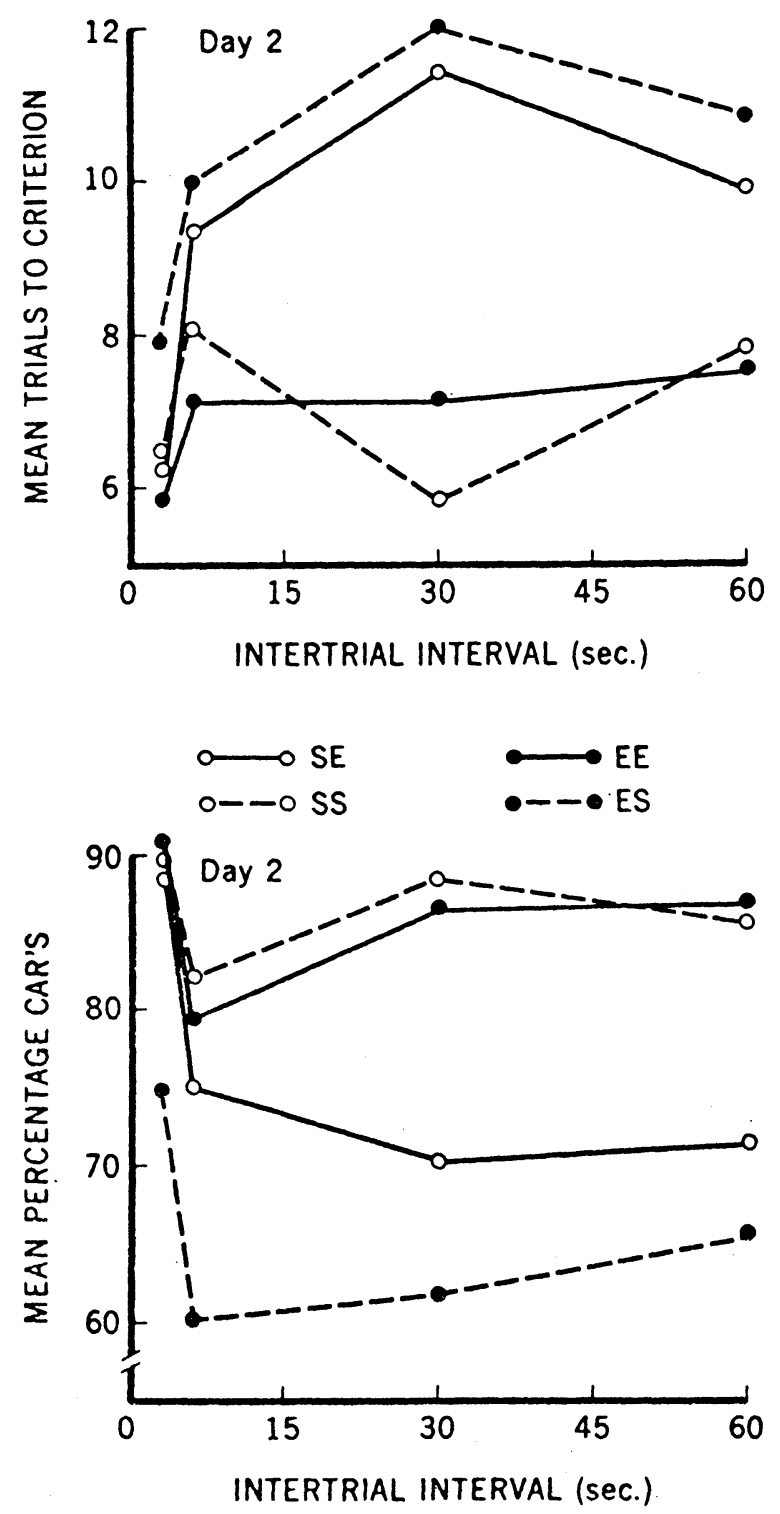

Fig. 1. Day 2 avoidance performance as a function of the intertrial TGF interval. 
Table 2

Analysis of State-Dependent Effects (F Test, df $=1 / 144)$

\begin{tabular}{|c|c|c|c|c|c|c|}
\hline \multirow{2}{*}{$\begin{array}{c}\text { Behavioral } \\
\text { Measure }\end{array}$} & \multirow[b]{2}{*}{ Treatment (Comparisons) } & \multicolumn{4}{|c|}{ Time on Grid Floor } & \multirow{2}{*}{$\begin{array}{c}\text { Overall } \\
\text { Effect }\end{array}$} \\
\hline & & $3 \mathrm{Sec}$ & $6 \mathrm{Sec}$ & $30 \mathrm{Sec}$ & $60 \mathrm{Sec}$ & \\
\hline $\begin{array}{l}\text { Trials to } \\
\text { Criterion }\end{array}$ & $\begin{array}{l}\text { Drug Day } 1 \text { by Drug Day } 2 \\
\text { SS vs SE } \\
\text { EE vs ES } \\
\text { SS vs EE } \\
\text { SE vs ES }\end{array}$ & $\begin{aligned} & 2.07 \\
< & 1 \\
& 9.92 \dagger \\
< & 1 \\
& 6.73^{* *}\end{aligned}$ & $\begin{aligned} & 4.24^{* *} \\
& 1.94 \\
& 3.56^{*} \\
< & 1 \\
< & 1\end{aligned}$ & $\begin{array}{l}27.61 \dagger \\
15.59 \dagger \\
32.05 \dagger \\
<1 \\
<1\end{array}$ & $\begin{aligned} & 5.64^{* *} \\
& 3.05^{*} \\
& 7.56 \dagger \\
< & 1 \\
< & 1\end{aligned}$ & $\begin{array}{l}29.22 \dagger \\
11.26 \dagger \\
19.72 \dagger \\
<1 \\
3.04^{*}\end{array}$ \\
\hline $\begin{array}{l}\text { Percentage } \\
\text { of CARs }\end{array}$ & $\begin{array}{l}\text { Drug Day } 1 \text { by Drug Day } 2 \\
\text { SS vs SE } \\
\text { EE vs ES } \\
\text { SS vs EE } \\
\text { SE vs ES }\end{array}$ & $\begin{aligned} & 5.45^{* *} \\
&< 1 \\
& 20.24 \dagger \\
&< 1 \\
& 13.63 \dagger\end{aligned}$ & $\begin{array}{c}44.92 \dagger \\
7.05^{* *} \\
43.36 \dagger \\
<1 \\
26.21 \dagger\end{array}$ & $\begin{array}{l}92.26 \dagger \\
44.18 \dagger \\
69.00 \dagger \\
<1 \\
53.16 \dagger\end{array}$ & $\begin{array}{l}64.13 \dagger \\
25.53 \dagger \\
43.15 \dagger \\
<1 \\
21.95 \dagger\end{array}$ & $\begin{array}{l}250.60 \dagger \\
48.80 \dagger \\
230.00 \dagger \\
<1 \\
63.31 \dagger\end{array}$ \\
\hline
\end{tabular}

between drug on Day 1 and drug on Day 2. As can be seen in Fig. 1, this interaction indicates that groups trained and tested under the same drug (SS and EE) tended to have a significantly higher percentage of CARs on Day 2 and took significantly fewer trials to reacquire criterion level performance than did groups trained and tested under different drug states (ES and SE). Collapsing across TGF conditions, the Drug on Day 1 by Drug on Day 2 interaction was significant for both the trials to criterion $[F(1,144)=29.22, p<.01]$ and \%CAR $[\mathrm{F}(1,144)=250.60, \mathrm{p}<.01]$ measures. Additionally, the TGF factor and the TGF by Drug interaction factor were significant for both the trials to criterion measure $[\mathrm{F}(3,144)=18.42, \mathrm{p}<.01$ and $\mathrm{F}(3,144)=13.19, \mathrm{p}<.01$, respectively $]$ and \%CAR measure $[F(3,144)=25.39, p<.01$ and $F(3,144)=$ $12.23, \mathrm{p}<.01$, respectively]. These latter analyses indicate that the drug interaction (Day 1, Day 2) differed across TGF conditions.

In order to examine the manner in which the TGF condition affected the drug conditions on Day 2, comparisons among appropriate drug groups were made (simple effects analysis) and are presented in Table 2 along with the Drug on Day 1 by Drug on Day 2 analysis. As can be seen in Table 2, the drug interaction is weakest at shortest TGF intervals and strongest at the longer TGF intervals. The individual group comparisons show that the EE and SS groups were not significantly different from one another on either behavioral measure at any TGF period. The SE group displayed generally poorer performance than the SS group for the trials to criterion and \%CAR measures at longer TGF periods but not at shorter TGF periods. In contrast, the ES group displayed generally poorer performance than its control group (EE) on these measures at all TGF periods. Furthermore, the ES group had significantly poorer Day 2 performance than did the SE group on both behavioral measures at the shortest TGF interval.

\section{DISCUSSION}

The results of the present experiment indicate that the duration of time spent on the grid floor of the avoidance chamber between trials significantly affects both the rapidity of one-way active avoidance acquisition and the pattern of retraining performance in the drug transfer paradigm. Shorter TGF periods were associated with fewer trials to criterion on Day 1 and impaired Day 2 retraining performance in the ES but not the SE group (asymmetrical dissociation) for the trials to criterion and \%CAR measures. The longer TGF periods were associated with a greater number of trials to achieve criterion performance on Day 1 and symmetrical state-dependent effects during Day 2 retraining, i.e., both the ES and SE groups were impaired relative to their controls. Thus, for the trials to criterion and percentage of CARs measures, the TGF treatment seemed to differentially affect Day 2 performance in the SE but not the ES group. Perhaps the set of variables influencing transfer of learning from training to testing sessions is somewhat different for the ES and SE groups.

In the present experiment, the variables differentially influencing testing performance in the ES and SE groups seem related to the motivational level of the animal. That animals with longer TGFs take longer to reach criterion performance may reflect faster extinction of that complex of autonomic and somatic responses (fear) conditioned to the grid floor, thus reducing the motivational basis for avoidance responding. Such an interpretation is similar to Baum's (1970) "response flooding" hypothesis, in which an animal confined in a fear-producing situation for some time with no possibility of escape extinguishes subsequent avoidance responding rapidly. Another interpretation has been offered by Denny (1971) whereby the ability of the animal to develop "relaxation" in the "safe" chamber of the avoidance apparatus would facilitate acquisition, while any development of relaxation in the shocked portion of the one-way apparatus would retard avoidance acquisition. If, in the present experiment, relaxation developed while the animal was on the grid floor at the longer TGF intervals, it would compete with effective avoidance responding. Furthermore, in our experiment, the ratio of "safe platform time" (a 
constant $15 \mathrm{sec}$ ) to TGF decreased with increasing TGF, a result which according to Denny would produce rapid acquisition at a short TGF and slower acquisition with a longer TGF. To the extent that a motivational interpretation of the TGF variable is correct, the Day 2 dissociation effects in the SE group may not be present under those conditions (brief TGF periods) which foster a high level of motivation (or at least rapid acquisition) for avoidance responding but may be manifest under those conditions (longer TGF periods) which foster a lower level of motivation (or at least lower rates of acquisition) for avoidance responding. Dissociation of avoidance responding in the ES group according to the latter interpretation apparently would not be affected by this particular set of motivational parameters.

In a more recent study (Wansley \& Holloway ${ }^{2}$ ), we have found that rats in a spontaneous alternation task (repeated access to the arms of a T-maze) displayed an intersession reduction in alternations under conditions of SS, SE, or EE on the two sessions at either a 0.5 - or a $1.5-\mathrm{g} / \mathrm{kg}$ dose level, while the ES group displayed an intersession increase in alternations. However, at a $2.0 \mathrm{~g} / \mathrm{kg}$ dose level, both the SE and ES groups displayed significantly more second-session alternations relative to their controls. The relative increases in alterations on Day 2 in the latter groups would seem to reflect a failure to transfer habituation of exploratory activity from the Day 1 session. Such data also suggest differences in transfer of learning in the ES and SE groups. Overton $(1968,1972)$ discusses the problem of assymetrical dissociation in terms of an interaction of basically symmetrical state dependency with other effects of the drug. We do not question the difficulty in interpreting results in the 2 by 2 drug transfer paradigm. Nor do we question differential responding based on the discriminability of drug states. Rather, we suggest that the transfer of learning functions for the ES and SE conditions are either based on different mechanisms or are differentially affected by certain experimental parameters, such as level of motivation. In the drug discrimination paradigm, such motivational factors may only be apparent during the initial phase of acquisition.

\section{REFERENCES}

Baum, M. Extinction of avoidance responding through response prevention (flooding). Psychological Bulletin, 1970, 74, 276-284.

Berger, B. D., \& Stein, L. An analy sis of the learning deficits produced by scopolamine. Psychopharmacologia (Berlin), 1969, 14, 271-283.

Crow, L. T. Effects of alcohol on conditioned avoidance responding. Physiology \& Behavior, 1966, 1, 89-91.

Denny, M. R. Relaxation theory and experiment. In F. R. Brush (Ed.), Avoidance conditioning and learning. New York: Acad emic Press, 1971. Pp. 235-296.

Holloway, F. A. State-dependent effects of ethanol on active and passive avoidance learning. Psychopharmacologia (Berlin), $1972,25,238-261$.

Overton, D. A. Dissociated learning in drug states (state dependent learning). In D. H. Efron (Ed.), Psychopharmacology, a review of progress 1957-1967. Washington, D.C: American College of Neuropharmacology and Psychopharmacological Research Branch of National Institute of Mental Health, 1968. Pp. 918-930.

Overton, D. A. State dependent learning produced by alcohol and its relevance to alcoholism. In $B$. Kissen and $H$. Begleiter (Eds.), The biology of alcoholism, Vol. II: Physiology and behavior. New York: Plenum Press, 1972.

\section{NOTES}

1. Holloway, F. A., \& Wansley, R. A. One-way avoidance acquisition and the intertrial time on grid floor. Submitted for publication.

2. Wansley, R. A., \& Holloway, F. A. State-dependent effects of ethanol on spontaneous alternation in rats. In preparation.

(Received for publication March 1, 1973; revision received November $20,1973$. 